\title{
Bioatividade de indutores de resistência no manejo da antracnose da goiabeira (Psidium guajava L.)
}

\author{
Rommel dos Santos Siqueira Gomes ${ }^{1}$, Andréa Celina Ferreira Demartelaere ${ }^{1}$, Luciana Cordeiro do Nascimento ${ }^{1}$, \\ Wendel Oliveira Maciel², Danilo Bruno Néri da Silva Wanderley ${ }^{1}$
}

${ }^{1}$ Departamento de Fitotecnia e Ciências Ambientas, Universidade Federal da Paraíba, Campus II, Areia, PB, CEP. 58.5397-000. ${ }^{2}$ Departamento de Fitopatologia, Universidade Federal de Lavras, Lavras, MG, CEP. 37.200-000.

Autor para correspondência: Rommel dos Santos Siqueira Gomes (pratacca@gmail.com).

Data de chegada: 11/06/2015. Aceito para publicação em: 29/07/2015.

$10.1590 / 0100-5405 / 2103$

\section{RESUMO}

Gomes, R.S.S.; Demartelaere, A.C.F.; Nascimento, L.C.; Maciel, W.O.; Wanderley, D.B.N.S. Bioatividade de indutores de resistência no manejo da antracnose da goiabeira (Psidium guajava L.). Summa Phytopathologica, v.42, n.2, p.149-154, 2016.

A cultura da goiaba apresenta perdas em torno de 40 a $60 \%$ na póscolheita relacionadas a problemas fitossanitários, como a antracnose causada pelo fungo Colletotrichum gloeosporioides. Pesquisas com métodos alternativos utilizando indutores de resistência têm sido bastante promissoras na busca de produtos com alto potencial no controle de patógenos em pós-colheita. Assim, o presente trabalho teve como objetivo avaliar os indutores de resistência no controle da antracnose e seus efeitos na qualidade físico-química em frutos de goiabeira 'Paluma'. Os tratamentos utilizados foram: Agro-mós ${ }^{\circledR}$, Ecolife $^{\circledR}$, Fosfitonova $\mathrm{K}^{\circledR}$, Cuprogarb $500^{\circledR}$, Rocksil $^{\circledR}$ e testemunha (água destilada esterilizada). Realizou-se o teste $i n$ vitro, com discos de colônia de C. gloeosporioides $(0,45 \mathrm{~cm}$ de diâmetro) com sete dias de cultivo e, postos em meio de cultura BDA acrescidos com os indutores. Foi determinada a porcentagem de inibição do crescimento micelial de C. gloeosporioides. O ensaio in vivo foi realizado com frutos de goiabeira variedade Paluma, desinfestados e tratados com indutores. Em seguida, discos de colônia do C. gloeosporioides foram inoculados e do primeiro ao oitavo dia após a inoculação, foram feitas avaliações do diâmetro das lesões nos frutos. As análises pós-colheita foram realizadas, avaliando a perda de massa fresca, sólidos solúveis totais (SST), acidez titulável (AT), razão SST/AT e potencial hidrogeniônico $(\mathrm{pH})$. Foi utilizado o delineamento inteiramente casualizado, em esquema de parcela subdivididas 6x8 (tratamentos x período de avaliação) e as médias comparadas pelo teste de Tukey a $5 \%$ de probabilidade. Os indutores Agro-mos ${ }^{\circledR}$, Ecolife $^{\circledR}$, Fosfitonova $\mathrm{K}^{\circledR}$, Cuprogarb $500^{\circledR}$ e Rocksil ${ }^{\circledR}$ inibiram o crescimento micelial do C. gloeosporioides in vitro, reduziram o diâmetro das lesões e mantiveram a qualidade pós-colheita em frutos de goiabeira 'Paluma'.

Palavras-chave: Colletotrichum gloeosporioides, Goiaba, Indução de resistência, Substâncias fungitóxicas

ABSTRACT

Gomes, R.S.S.; Demartelaere, A.C.F.; Nascimento, L.C.; Maciel, W.O.; Wanderley, D.B.N.S. Bioactivity ofresistance inductors in the management of guava (Psidium guajava L.) anthracnose. Summa Phytopathologica, v.42, n.2, p.149-154, 2016.

The culture of guava present losses around $40-60 \%$ in postharvest related to phytosanitary problems such as anthracnose caused by Colletotrichum gloeosporioides. Research on alternative methods using resistance inductors have been quite promising in the search for products with high potential in the control of pathogens in postharvest. The present study aimed to evaluate the resistance inducers in controlling anthracnose and its effects on physical and chemical quality in fruits of guava 'Paluma'. The treatments were: Agro-mós ${ }^{\circledR}$, Ecolife $^{\circledR}$, Fosfitonova $\mathrm{K}^{\circledR}$, Cuprogarb $500^{\circledR}$, Rocksi ${ }^{\circledR}$ and witness (distilled water and sterile). The in vitro test with C. gloeosporioides colony discs $(0,45 \mathrm{~cm}$ diameter) with seven days of culture and put into PDA culture medium added with elicitors. It was determined the percentage of inhibition of mycelial growth of $C$. gloeosporioides. And the in vivo test was conducted with fruit variety of guava Paluma, disinfected and treated with elicitors then C. gloeosporioides colony discs were inoculated and the first to the eighth day, evaluations were made of lesions diameter in the fruit sand was also performed post-harvest analysis, assessing the loss of fresh mass, total soluble solids (TSS), titratable acidity (TA), reason TSS/TA and hydrogenic potential $(\mathrm{pH})$. It was used a completely randomized design in a split plot design $6 \times 8$ (treatments $\mathrm{x}$ evaluation period) and the averages compared by Tukey test at $5 \%$ probability. The elicitors Agro-mos $^{\circledR}$, Ecolife ${ }^{\circledR}$, Fosfitonova $\mathrm{K}^{\circledR}$, Cuprogarb $500^{\circledR}$ and Rocksil ${ }^{\circledR}$ inhibited the mycelial growth of $C$. gloeosporioides in vitro, reduces the lesions diameter and maintained post-harvest quality fruit guava 'Paluma'.

Keywords: Colletotrichum gloeosporioides, Guava, Induction of resistance, fungitoxic substances

O Brasil produziu na safra de 2014 em torno de 500 mil toneladas de goiaba (Psidium guajava L.) (9). Os estados de São Paulo, Pernambuco e Minas Gerais são responsáveis por $69 \%$ da produção nacional, destacando-se pela preferência no mercado consumidor, por apresentar em sua constituição, alto teor de vitamina C (ácido ascórbico), vitaminas do complexo B, $\beta$-caroteno, licopeno e açúcares totais (20), além de possuir coloração, sabor e aroma desejáveis tanto para a indústria, na produção de doces, geléias, pastas e frutas em calda, como também para o consumo in natura (14).

Pesquisas na área da pós-colheita visam esclarecer as alterações metabólicas, como os processos físicos, físico-químicos, químicos e bioquímicos que ocorrem em frutos mesmo depois de colhidos, pois, continuam desempenhando funções ativas do metabolismo vegetal, como respiração e transpiração (6) e esses processos podem ser 
acelerados principalmente se ocorrerem injúrias provocadas por danos mecânicos ou pelo ataque de patógenos. Para manter a integridade dos frutos principalmente no comércio in natura, tem-se utilizado estratégias de controle, físico, químico e biológico,que possam reduzir as perdas,proporcionando frutos com alta qualidade, ampliando o tempo de armazenamento e sem alterar as características organolépticas que são as preferidas pelos consumidores (30).

Estudos sobre cultivo in vitro com Colletotrichum gloeosporioides (Penz.) Sacc. têm sido realizados para facilitar a compreensão a respeito das exigências nutricionais exercidas pelo patógeno e que podem está relacionada com os meios de cultura, temperatura, luminosidade e potencial hidrogênionico, tornando fatores decisivos para o sucesso no crescimento das estruturas fúngicas como crescimento micelial e produção de conídios (24). Esses fatores influenciam no entendimento de todo o ciclo do patógeno, já que é responsável por causar doenças de grande importância econômica para a cultura da goiabeira como a antracnose (18).

A utilização de produtos alternativos, como os indutores em póscolheita de frutos tem sido bastante promissor na busca de produtos de melhor qualidade com alto potencial no controle de fitopatógenos, devido a presença de compostos químicos com ação direta, provocando efeito fungistático através da ativação de algumas enzimas como a fenilalanina amônia-liase (FAL), que pode influenciar no acúmulo de compostos fenólicos ou pela ação indireta através da indução resistência (29), envolvendo a ativação de mecanismos de defesa latentes e ou já existente nas plantas em resposta ao tratamento com agentes bióticos ou abióticos. Este mecanismo refere-se às defesas bioquímicas e estruturais pós-formadas, de maneira não específica e por meio da ativação de genes envolvidos, influenciando no controle de doenças (28).

Portanto, o presente trabalho teve como objetivo avaliar os indutores de resistência no controle da antracnose e seus efeitos na qualidade físico-química em frutos de goiabeira 'Paluma'.

\section{MATERIAL E MÉTODOS}

Os experimentos foram conduzidos no Laboratório de Fitopatologia do Departamento de Fitotecnia e Ciências Ambientais da Universidade Federal da Paraíba, Areia, PB.

\section{Preparo dos indutores}

Os tratamentos à base de indutores de resistência foram estabelecidos seguindo as concentrações determinado pelo fabricante (Tabela 1) e a testemunha composta apenas de água destilada e esterilizada (ADE), aplicando-se alíquotas de $50 \mu \mathrm{L}$ de cada tratamento sobre os discos de micélio do C. gloeosporioides e nos frutos foi até o ponto de escorrimento.

\section{Teste in vitro}

O isolado de C. gloeosporioides foi obtido a partir de frutos de goiabeira com sintomas típicos da doença. Procedeu-se o isolamento em meio BDA ( $200 \mathrm{~g}$ de extrato de batata, $20 \mathrm{~g}$ dextrose, $20 \mathrm{~g}$ ágar $\left.\mathrm{L}^{-1}\right)$ e incubação por sete dias em temperatura ambiente $\left(25 \pm 2^{\circ} \mathrm{C}\right)$. Para identificação do patógeno foram realizadas análises macro e microscópicas e comparação com literatura especializada (15). Observou-se a pigmentação, textura, consistência e forma do verso e reverso das colônias desenvolvidas in vitro.

Para a multiplicação do patógeno, retirou-se um disco da colônia (0,45 cm de diâmetro) e colocados em meio de cultura BDA, sob temperatura $\left(25 \pm 2{ }^{\circ} \mathrm{C}\right)$, regime de luz alternada $(12 \mathrm{~h}$ claro e $12 \mathrm{~h}$ escuro) e incubada durante sete dias em câmara do tipo B.O.D.

Em seguida, foram retirados discos da colônia de C. gloeosporioides e postos em meio de cultura BDA, aplicando-se os tratamentos sobre os discos de micélio,nas concentrações descritas anteriormente e armazenados em B.O.D com temperatura $\left(25 \pm 2{ }^{\circ} \mathrm{C}\right)$ e regime de luz alternado.Do primeiro ao quinto dia após a inoculação, com auxílio de uma régua centrimetrada, foi realizada a mensuração da colônia em dois eixos ortogonais até atingir toda a placa,e o cálculo da porcentagem de inibição do crescimento micelial (ICM), conforme a fórmula descrita por Abbott (1): ICM (\%) $=\left[(\mathrm{T}-\mathrm{t})^{*} 100\right] / \mathrm{T}$, onde T é a testemunha e t, o tratamento.

\section{Teste in vivo}

Os frutos de goiabeira variedade Paluma foram adquiridos no Centro Estadual de Abastecimento e Serviço Autônomo (CEASA) em Campina Grande, PB. As goiabas, apresentavam estádio de maturação 3 , o qual é definido pela coloração da casca verde-amarelo de acordo com a classificação feita por Azzolini et al. (3) e selecionadas quanto à ausência de danos mecânicos e podridões.Em seguida, foi feito a desinfestação dos frutos com a solução de hipoclorito de sódio a $0,3 \%$ por 3 minutos e tripla lavagem em água destilada sendo colocados sobre papel toalha para a secagem.

Foram aplicados os indutores nos frutos nas concentrações descritas anteriormente com ajuda de um pulverizador manual com capacidade para $250 \mathrm{~mL}$. Após $24 \mathrm{~h}$ da aplicação dos indutores foi feito um ferimento na região equatorial dos frutos, com diâmetro de aproximadamente 0,03 e $2 \mathrm{~mm}$ de profundidade com auxílio de um perfurador de metal flambado. Sobre o ferimento foidepositadoum disco de micélio do C. gloeosporioides com sete dias de cultivo, eos frutos acondicionados em câmara úmida (sacos de polipropileno)durante $48 \mathrm{~h}$.

Foram realizadas avaliações nos frutos do primeiro ao oitavodia, medindo o diâmetro $(\mathrm{cm})$ das lesões em dois eixos ortogonais, com auxílio de uma régua centimetrada.

\section{Análises físico-químicas}

Perda de massa fresca (PMF): foi realizada a cada dois dias, pesando os fruto sem balança Filizolasemi-analítica, com capacidade para $15 \mathrm{~kg}$ e sensibilidade para $5 \mathrm{~g}$, tomando-se como base o peso inicial. Os resultados foram expressos em porcentagem de perda de massa fresca, através do calculo $\mathrm{PMF}(\%)=[(\mathrm{Pi}-\mathrm{Pj}) / \mathrm{Pi}]^{*} 100$, onde: $\mathrm{Pi}=$ peso inicial

Tabela 1. Descrição dos indutores de resistência utilizados no controle da antracnose da goiabeira (Psidium guajava L.).

\begin{tabular}{lllc}
\hline Produto comercial & Fabricante & Composição & Concentração recomendada \\
\hline Agro-mos $^{\circledR}$ & Improcrop & Sulfato de cobre, sulfato de zinco e complexado por aminoácidos. & $2,0 \mathrm{~mL} \mathrm{~L}^{-1}$ \\
Ecolife & Quinabra & Bioflavonóides, ácido ascórbico, ácido lático e glicerina vegetal. & $2,0 \mathrm{~mL} \mathrm{~L}^{-1}$ \\
Fosfitonova $\mathrm{K}^{\circledR}$ & Fertinova & Pentóxido de fósforo $\left(\mathrm{P}_{2} \mathrm{O}_{5}\right)$ e Óxido de potássio $\left(\mathrm{K}_{2} \mathrm{O}\right)$. & $0,5 \mathrm{~g} \mathrm{~L}^{-1}$ \\
Cuprogorb $500^{\circledR}$ & Oxiquimica agrociência & Oxicloreto de cobre & $3,0 \mathrm{~g} \mathrm{~L}^{-1}$ \\
Rocksil $^{\circledR}$ & Lia ulmasud & Óxido de alumínio e dióxido de silício e enxofre & $1,0 \mathrm{~g} \mathrm{~L}^{-1}$ \\
\hline
\end{tabular}


dos frutos e $\mathrm{Pj}$ = peso no período subsequente a $\mathrm{Pi}$.

Sólidos Solúveis Totais (SST): obtido através do suco extraído de frutos cortados longitudinalmente e determinado em refratômetro digital, com correção automática de temperatura, sendo os resultados expressos em ${ }^{\circ} \operatorname{Brix}(2)$.

Acidez titulável (AT): foi obtida a partir da titulação de $50 \mathrm{~mL}$ de suco com uma solução de hidróxido de sódio a 0,3125 de normalidade e usando-se a fenoftaleína como indicadora e expresso em porcentagem de ácido cítrico $100 \mathrm{~g}^{-1}(10)$.

Razão SST/AT: calculada através da divisão do teor de sólidos solúveis totais pela a acidez titulável.

Potencial hidrogeniônico $(\mathrm{pH})$ : foi extraída uma amostra de $5 \mathrm{~g}$ de suco, homogeneizada em $50 \mathrm{~mL}$ deADE. A leitura do $\mathrm{pH}$ do suco diluído foi realizada através de um $\mathrm{pHmetro}$ de bancada que possui correção automática dos valores em função da temperatura (2).

\section{Análise estatística}

$\mathrm{O}$ experimento foi realizado em delineamento inteiramente casualizado, em esquema de parcela subdividida $6 \times 8$ (tratamentos $\mathrm{x}$ período de avaliação), com três repetições de cinco frutos cada. As médias foram comparadas pelo teste de Scott-knott a $5 \%$ de probabilidade no software estatístico ASSISTAT $^{\circledR}$ versão beta 7.7 (25).

\section{RESULTADOS E DISCUSSÃO}

Quando utilizados o Agro-mos ${ }^{\circledR}$, Ecolife ${ }^{\circledR}$, Fosfitonova $\mathrm{K}^{\circledR}$, Cuprogorb $500^{\circledR}$ e Rocksil ${ }^{\circledR}$ em meio BDA, verificou-se diferença significativa entre os tratamentos em função do período de armazenamento,observando-se redução na porcentagem de inibição do crescimento micelial de C. gloeosporioides. Apenas o tratamento a base de Ecolife ${ }^{\circledR}$ permaneceu com ação fungitóxica no último dia de avaliação, conforme as Figuras 1A,B,C,D e E.

Pode-se afirmar que ocorreu efeito fungitóxico no controle do $C$. gloeosporioides in vitro. De acordo com Smith (26) os indutores têm sido amplamente usados como métodos de controle alternativo de patógenos, pois possuem moléculas eliciadoras de origem biótica ou abiótica que podem ter ação fungitóxica (mecanismo direto), ou ainda estimular a produção de metabólitos vegetais como proteínas, enzimas, hormônios e vitaminas, evitando ou retardando o estabelecimento do patógeno no tecido do hospedeiro (28).

Comportamento semelhante ao presente trabalho foi observado por Motoyama et al. (16) utilizando Ecolife ${ }^{\circledR}$, verificaram atividade antifúngica in vitro contra $C$. lagenarium. Sousa et al. (26) avaliaram o efeito fungitóxico do óleo de neen (Azadiractha indica A. Juss), adicionados 0,$2 ; 0,4 ; 0,6 ; 0,8$ e 1,0\% em meio de cultura BDA sobre o desenvolvimento de $C$. gloeosporioides in vitro e constataram que em todas as concentrações utilizadas, ocorreu a inibição do crescimento micelial. Rozwalka et al. (22) testaram extratos e óleos essenciais de plantas medicinais e aromáticas sobre C.gloeosporioides, in vitro, demonstraram que houve inibição total ou parcial do crescimento.

Verificou-se que em todos os tratamentos com indutores houve redução do diâmetro das lesões nos frutos de goiabeira quando comparados com a testemunha (ADE) até o oitavo dia de armazenamento (Figuras 2A,B,C,D e E).Outra ação relacionada ao efeito dos indutores foi a redução da severidade da antracnose. Esse fenômeno pode ser explicado através da ativação de genes da planta provocados por fatores bióticos (como microrganismos viáveis ou inativados) ou abióticos, capazes de ativar ou induzir qualquer resposta de defesa, envolvendo mecanismos bioquímicos e estruturais pré e pós-formados (8). Essa indução pode desencadear uma série de eventos como as explosões oxidativas, respostas de hipersensibilidade, acúmulo de proteínas relacionadas à patogênese como quitinases e $\beta-1,3-$ glucanases, enzimas envolvidas na rota dos fenilpropanóides como fenilalanina amônia-liase, outras como polifenoloxidase e peroxidase e a síntese de fitoalexinas (28).

Neste trabalho apresentou redução na severidade da doença,corroborando com o estudo realizado por Lemos et al. (12),
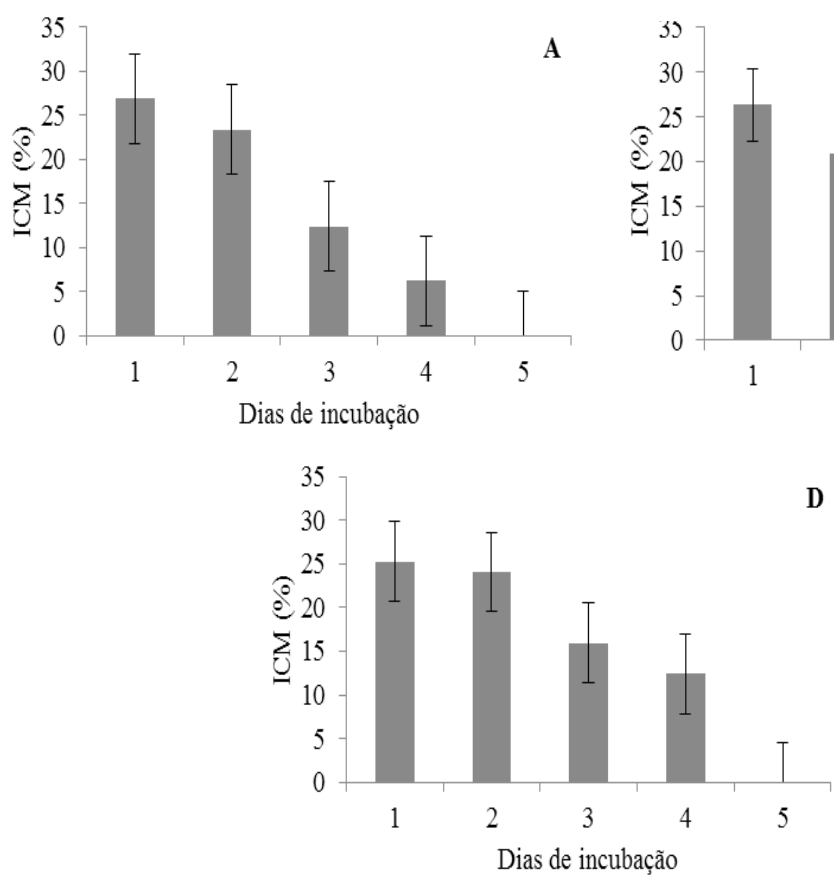

D
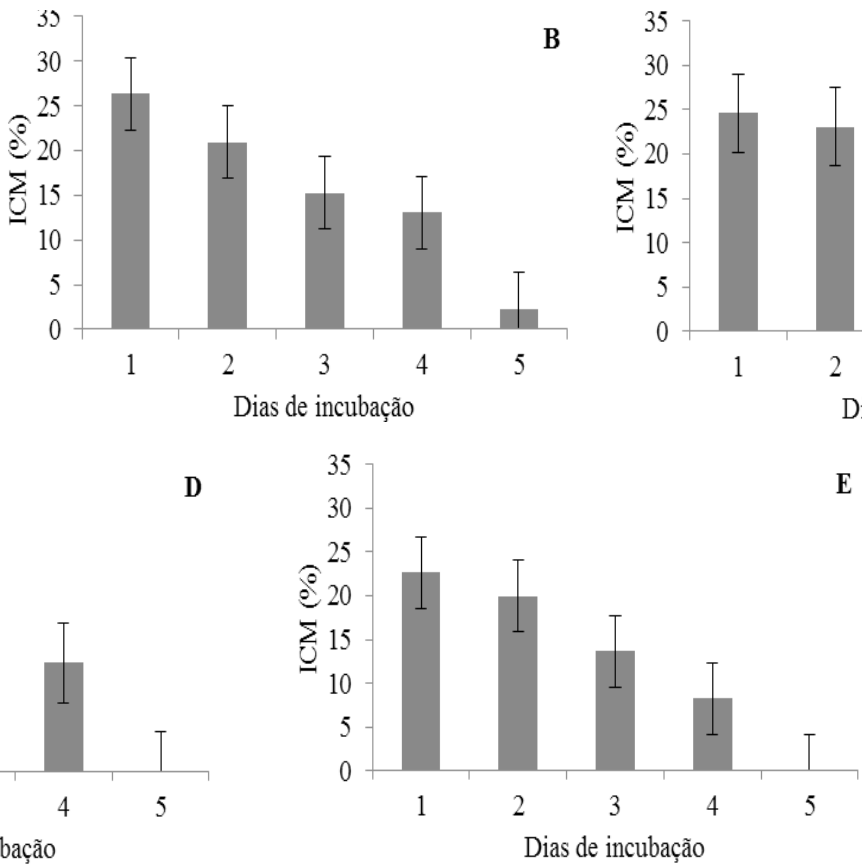

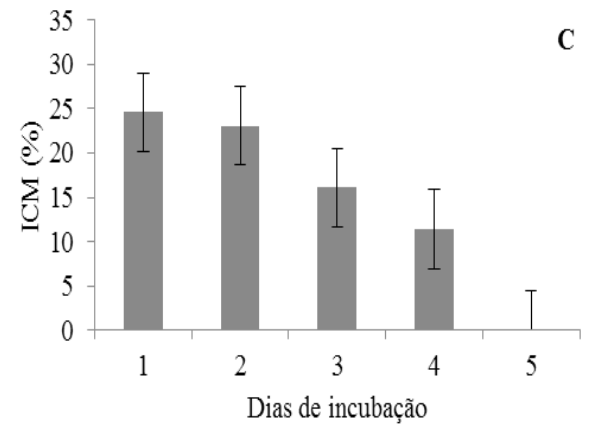

Figuras 1. Inibição do crescimento micelial (ICM) de Colletotrichum gloeosporioides, submetido aos tratamentos com indutores de resistência: $\operatorname{Agro-mos}^{\circledR}$ (A), Ecolife ${ }^{\circledR}$ (B), Fosfitonova $K^{\circledR}$ (C), Cuprogarb $500^{\circledR}$ (D) e Rocksil ${ }^{\circledR}$ (E). 

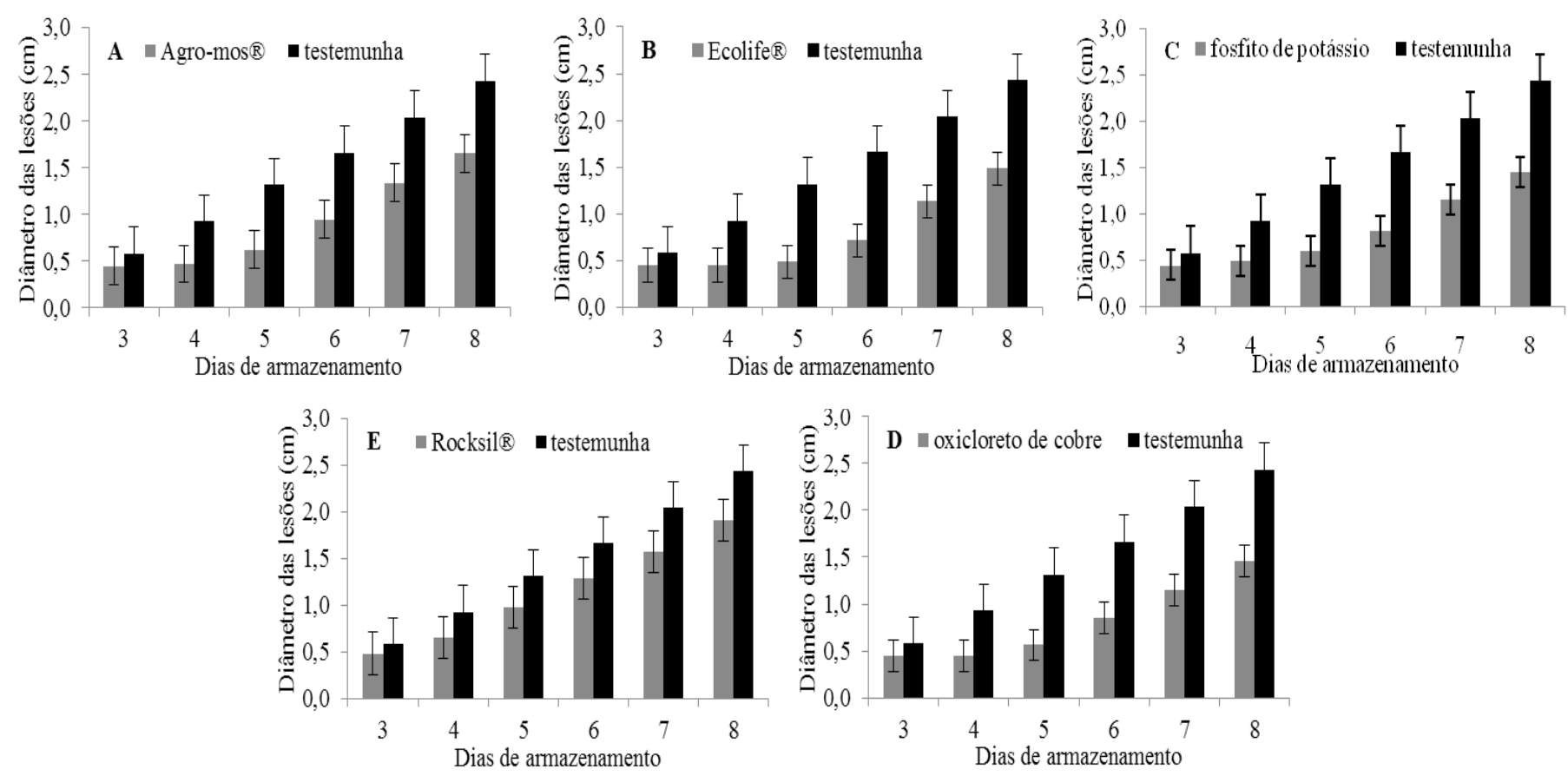

Figuras 2. Diâmetro das lesões em frutos de Psidium guajava 'Paluma', tratados com Agro-mos ${ }^{\circledR}(\mathrm{A})$, Ecolife ${ }^{\circledR}(\mathrm{B})$, Fosfitonova $\mathrm{K}^{\circledR}(\mathrm{C})$, Cuprogarb $500^{\circledR}(\mathrm{D})$ e $\operatorname{Rocksil}^{\circledR}(\mathrm{E})$.

quando avaliaram produtos alternativos no controle da antracnose na pós-colheita de manga 'Ubá' (Mangifera indica L.), observando que os frutos tratados com óleo de amêndoa de macaúba (Acrocomia aculeata (Jacq.) + LPI (leite em pó instantâneo) e Agro-mos ${ }^{\circledR}$, ocorreu redução da severidade atingindo seu máximo entre o sétimo e o oitavo dia após a inoculação. Nascimento et al. (19), avaliando o efeito de Bion ${ }^{\circledR}$, Agro-mos ${ }^{\circledR}$ e Ecolife ${ }^{\circledR}$ no controle da antracnose em mamoeiro (Carica papaya L.) verificaram que apenas o Bion $^{\circledR}$ se manteve eficiente no controle da doença, após nove dia depois da inoculação.

$\mathrm{Na}$ avaliação da perda de massa fresca, observou-se que o tratamento Ecolife ${ }^{\circledR}$ apresentou menor perda de massa fresca em relação aos demais tratamentos ao final do período de armazenamento, diferindo da testemunha (Figura 3A). Myoda et al. (17) afirmaram que essa manutenção da água dentro das células evita o murchamento
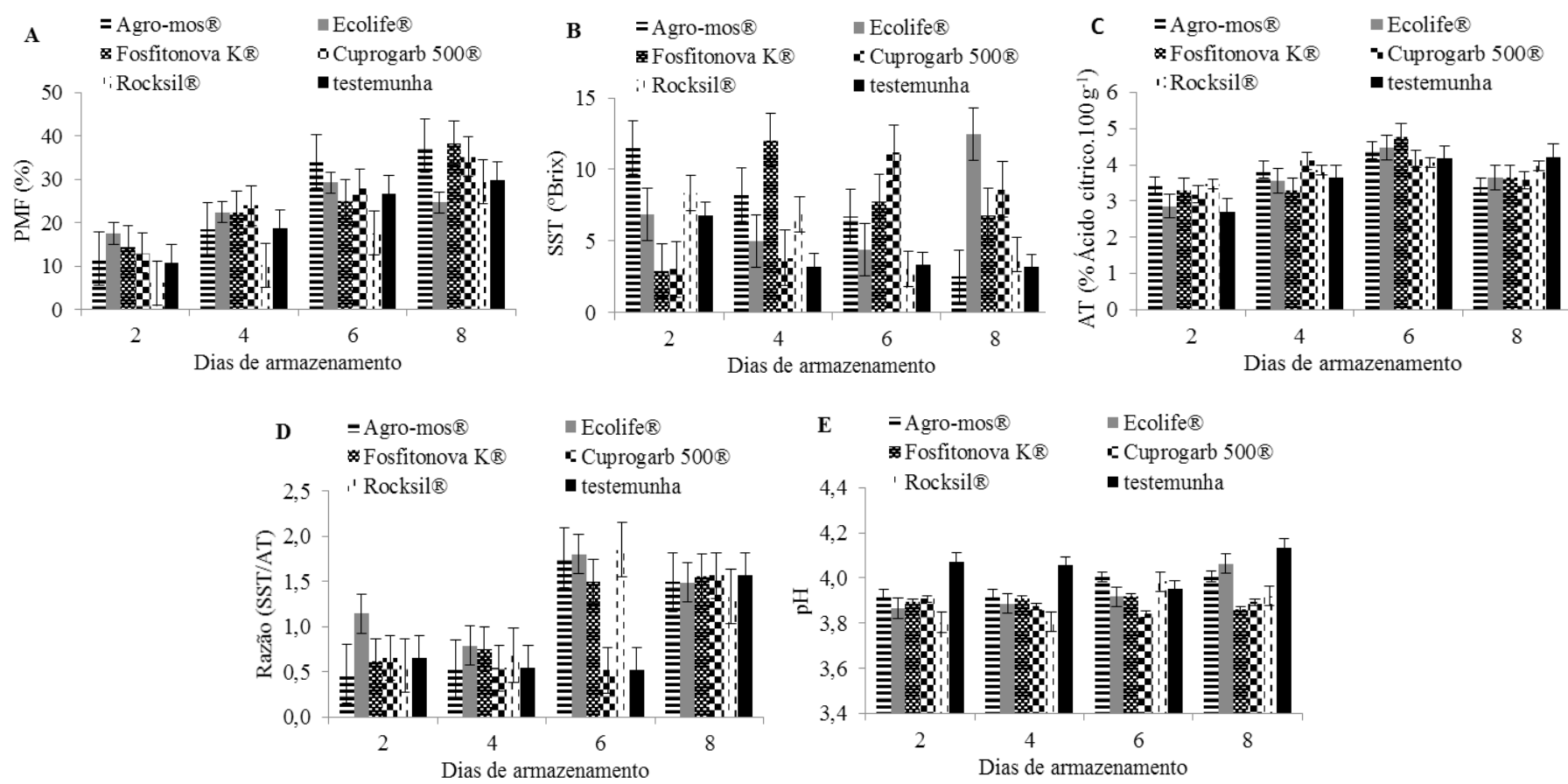

Figuras 3. Perda de massa fresca (PMF) (A), teores sólidos solúveis totais (SST) (B), acidez titulável (AT) (C), razão sólidos solúveis totais/ acidez titulável (SST/AT) (D) e valores de $\mathrm{pH}$ (E) nos frutos de Psidium guajava 'Paluma', submetidos aos tratamentos Agro-mos ${ }^{\circledR}$, Ecolife ${ }^{\circledR}$, Fosfitonova $\mathrm{K}^{\circledR}$, Cuprogarb $500^{\circledR}$ e Rocksil $^{\circledR}$. 
dos frutos, mantendo as qualidades texturais (amaciamento, perda da frescor e suculência), e nutricionais,preservando a qualidade dos frutos na pós-colheita.

O maior teor de SST foi obtido nos frutos tratados com Ecolife ${ }^{\circledR}$, diferindo estatisticamente dos demais tratamentos, com valores superiores em relação testemunha (Figura 3B). Portanto, verificase que apenas os tratamentos Ecolife ${ }^{\circledR}$ e Cuprogarb $500^{\circledR}$ obtiveram teores de SST próximos aos exigidos pelo mercado, variando entre 8,60 a $12,45^{\circ}$ Brix. Kusano et al. (11), avaliando as qualidades físicoquímica em frutos de goiabeira 'Paluma', também encontraram teores de SST bem próximos de 9,13 a 11,07, corroborando com os resultados obtidos no presente trabalho.A avaliação do teor de SST fornece um indicativo sobre o teor de açúcares nos frutos (13), portanto, importante na qualidade organoléptica destes, sendo desejáveis pelo mercado consumidor de frutos in natura de goiabeiras, valores acima de 10 ${ }^{\circ}$ Brix (7).

Foram verificados maiores teores de ácido cítrico em frutos de goiabeira quando utilizou-se os indutores Agro-mos ${ }^{\circledR}$, Ecolife ${ }^{\circledR}$ eFosfitonova $\mathrm{K}^{\circledR}$ no sexto dia de armazenamento (Figura 3C). A acidez, avaliada por meio da presença de ácidos orgânicos expressos em ácido cítrico, é de grande importância, pois esta diretamente relacionada ao estado de conservação dos frutos (4). Os padrões de qualidade para polpa de goiaba, estabelecidos pelo Ministério da Agricultura, Pecuária e Abastecimento, exigem teores de acidez total titulável expressa em ácido cítrico, mínimo de $0,40 \mathrm{~g} / 100 \mathrm{~g}$ de fruto (7).

Observa-se a maior relação SST/AT em frutos de goiabeira que receberam os tratamentos Fosfitonova $\mathrm{K}^{\circledR}$ e Cuprogarb $500^{\circledR}$ e ambos não diferiram da testemunha (Figura 3D).De acordo com Chitarra \& Chitarra (5), a relação SST/AT, indica que quanto menor a taxa de sólidos solúveis totais, maior será a acidez e, desta forma, poderá influenciar na diminuição da atividade respiratória e, consequentemente, reduzir a aceleração do metabolismo, retardando o processo de maturação dos frutos.

Valores de $\mathrm{pH}$ ideais em frutos de goiabeira foram obtidos quando utilizaram os tratamentos com Fosfitonova $\mathrm{K}^{\circledR}$, Cuprogarb $500^{\circledR} \mathrm{e}$ Rocksil $^{\circledR}$, conforme (Figura 3E). Werner et al. (31), avaliando frutos de goiabeira 'Cortibel', verificaram mesmo comportamento do presente trabalho, após 12 dias de armazenamento, onde ocorreu decréscimo no $\mathrm{pH}$ de 3,88 a 3,77. Coser et al. (7), avaliando as qualidade físicoquímica em frutos de goiabeira 'Paluma', encontraram valores de $\mathrm{pH}$ variando entre 3,0 a 4,1. De acordo com Yusof (32), a faixa de $\mathrm{pH}$ entre 3,0 e 4,1 indica que estão dentro dos valores estabelecidos para o padrão de qualidade aceito pelos consumidores e estão corroborando com os encontrados no presente trabalho.

Pode-se afirmar que a redução do $\mathrm{pH}$ no início do armazenamento pode estar associada a liberação de ácidos orgânicos, como o poligalacturônico no meio intracelular, decorrente do processo de quebra de parede celular e, consequentemente, amolecimento dos frutos. O produto final da degradação da parede celular, são ácidos orgânicos, contudo os radicais metil $\left(\mathrm{CH}_{3}^{-}\right)$liberados dentro de tal processo podem favorecer a alteração do $\mathrm{pH}(21)$.

Os indutores Agro-mos ${ }^{\circledR}$, Ecolife ${ }^{\circledR}$, Fosfitonova $\mathrm{K}^{\circledR}$, Cuprogarb $500^{\circledR}$ e Rocksil ${ }^{\circledR}$ inibiram o crescimento micelial deC. gloeosporioides in vitro, reduziram o diâmetro das lesões e incrementaram a qualidade pós-colheita em frutos de goiabeira 'Paluma'.

\section{REFERENCIAS}

1. Abbott, W.S. Method of computing the effectiveness of the insecticide. Journal of economic entomology,Cary, v.28, p.625-627, 1925.

2. AOAC: Association of Official Analytical Chemistry. Official methods of analysis of the Association of Official Analytical Chemistry. Washington: AOAC, 17th ed. 1115p. 2005.

3. Azzolini, M.; Jacomino, A.P.; Bron, I.U. Índices para avaliar qualidade pós-colheita de goiabas em diferentes estádios de maturação. Pesquisa Agropecuária Brasileira, Brasília, v.39, n.2, p.139-145, 2004.

4. Brunini, M.A.; Oliveira, A.L.; Varanda, D.B. Avaliação da qualidade de polpa de goiaba 'paluma' armazenada a $-20^{\circ} \mathrm{C}$.Revista Brasileira de Fruticultura, Jaboticabal, v.25, n.3, p.394-396, 2003.

5. Chitarra, M.I.F; Chitarra, A.B. Pós-colheita de frutas e hortaliças; fisiologia e manuseio. Lavras: ESAL-FAEPE, 320p. 1990.

6.Chitarra, M.I.F; Chitarra, A.B. Pós-colheita de frutas e hortaliças: fisiologia e manuseio. Lavras: ESAL-FAEPE, 785p. 2005.

7. Coser, S.M.; Ferreira, M.F.S.; Ferreira, A.; Saraiva, S. H. Diversidade genética de seleções de goiabeiras cortibel. Revista Brasileira de Fruticultura, Jaboticabal, v.36, n.2, p.391-399, 2014.

8.Hammerschimidt, D.; Dann, E.K. Inducedresistancetodisease. In: Rechcigl, N.A.; Rechcigl, J.E. (Ed.) Environmentaly safe approaches to crop disease control, Boca Raton: CRC-Lewis Publishers, p.177-199, 1997.

9. IBGE: Instituto Brasileiro de Geografia e Estatística. Estimativa da produção agrícola 2014. Disponível em: www.ibge.gov.br/. Acesso em: 03 de março de 2015.

10. IAL: Instituto Adolfo Lutz. Métodos físico-químicos para análise de alimentos. São Paulo: IAL, 4.ed. 1020p. 1.ed. digital. 2008.

11. Kusano, D.M.; Benett, K.S.S.; Rui, R.F.; Ferreira, K.R.; Silveira, M.V.; Luqui, L.L.; Rodrigues, E.T. Avaliação sensorial e preferência de cultivares de goiabeiras vermelhas na região de Aquidauana-MS, Revista Agrarian, Dourados, v.6, n.19, p.1-6, 2013.

12. Lemos, L.M.C.; Coutinho, P.H.; Salomão, L.C.C.; Siqueira, D.L.; Cecon, P.R. Controle da antracnose na pós-colheita de manga 'ubá' com o uso de produtos alternativos, Revista Brasileira de Fruticultura, Jaboticabal - SP, v.35, n.4, p.962-970, 2013.

13. Manica, I.; Kist, H.; Micheletto, E. L.; Krause, C. A. Competição entre quatro cultivares e duas seleções de goiabeira. Pesquisa Agropecuária Brasileira, Brasília, v.33, p.1305-1313, 1998.

14. Menezes, C.C.; Borges, S.V.; Cirillo, M.A.; Ferrua, F.Q.; Oliveira, L.F.; Mesquita, K.S. Caracterização física e físico-química de diferentes formulações de doce de goiaba (Psidiumguajava L.) da cultivar Pedro Sato. Ciência e Tecnologia de Alimentos, Campinas, v.29, n.3, p.618-625, 2009

15. Menezes, M. Aspectos Biológicos e Taxonômicos de Espécies do Gênero Colletotrichum. Anais da Academia Pernambucana de Ciência Agronômica, Recife, v.3, p.170-179, 2006.

16. Motoyama, M.M.; Schwan-Estrada, K.R.F.; Stangarlin, J.R.; Fiori-Tutida, A.C.G.; Scapim, C.A. Indução de fitoalexinas em soja e em sorgo e efeito fungitóxico de extratos cítricos sobre Colletotrichumlagenarium e Fusariumsemitectum. Acta Scientiarum.Agronomy, Maringá, v.25, p.491-496, 2003.

17. Myoda, T.; Fujimura, S.; Park, B.; Nagashima, T.; Nakagawa, J.; Nishizawa, M. Antioxidative and antimicrobial potential of residues of camu-camu juice production.Journal of Food,Agriculture \& Environment, Helsinki, v.8, n.2, p.304-307, 2010.

18. Nascimento, L.C.; Nery, A.R.; Rodrigues, L.N. Controle de Colletotrichumgloeosporioides em mamoeiro, utilizando extratos vegetais, indutores de resistência e fungicida. Acta Scientiarum.Agronomy, Maringá, v.30, n.3, p.313-319, 2008.

19.Nogueira Filho, R.M. Banana in natura na alimentação de alevinos de tilápia-do-nilooreochromisniloticus(linnaeus, 1758),como fonte de carboidrato na ração e noprocessamento de produto. Dissertação de Mestrado em Ciência Animal. Universidade Federal do Vale do São Francisco,60f. 2012.

20.Pommer, C.V.;Murakami, K.R.N. BreedingGuava (Psidiumguajava L.). In Jain, S.M.; Priyadarshan, P.M. (Org.). Breeding Plantation Tree Crops: Tropical Species. New York: Springer, v.1, p. 83-119, 2009.

21. Oliveira, L.F.M. Controle alternativo da antracnose durante a pós-colheita de goiabas 'Paluma' simulando armazenamento e a comercialização. Dissertação de Mestrado em Agrossistemas. Universidade 
Federal Sergipe, 105f. 2012.

22. Rozwalka, L.C.; Lima, M.L.R.Z.C.;Mio, L.L.M.;Nakashima, T. Extratos, decoctos e óleos essenciais de plantas medicinais e aromáticas na inibição de Glomerellacingulata e Colletotrichumgloeosporioides de frutos de goiaba. Ciência Rural, Santa Maria, v.38, n.2, p.301-307, 2008.

23. Shaner, G.; Finney, R.E. The effects of nitrogen fertilization on the expression of slowmildwing inknox wheat. Phytopathology,Saint Paul, v.67, p.1051-1055, 1977.

24. Silva, C.M.M.S.; Melo, I.S. Requisitos Nutricionais Para O Fungo Alternaria Alternata. Pesquisa Agropecuária Brasileira, Brasília, v.34, n.3, p.499-503, 1999.

25. Silva, F.A.S. Assistat - Programa de análises estatísticas, Versão 7.7 beta. Campina Grande: UAEG-CTRN-UFCG, 2012. Disponível em: http:// www.assistat.com/index.html. Acessoem: 02 Mar. 2014

26. Smith, C.J. Accumulation of phytoalexins: defense mechanisms and stimulus response system. New Phytologist.Hoboken, v.132, p.1-45,1996.

27. Sousa, R.M.S.; Serra, I.M.R.S.; Melo, T.A. Efeito de óleos essenciais como alternativa no controle de Colletotrichumgloeosporioides, em pimenta.SummaPhytopathologica, Botucatu, v.38, n.1, p.42-47, 2012

28. Stangarlin, J.R.; Kuhn, O. J.; Toledo, M.V.; Portz, R. L.; Schwanestrada, K.R.F.; Pascholati, S.F. A defesa vegetal contra fitopatógenos. Scientia Agraria Paranaensis, Marechal Cândido Rondon, v.10, n.1, p.18-46. 2011.

29. Stangarlin, J. R.; Schulz, D. G.; Franzener, G.; Assi, L. Schwanestrada, K. R. F.; Kuhn, O. J. Indução de fitoalexinas em soja e sorgo por preparações de Saccharomycesboulardii. Arquivos do Instituto Biológico, São Paulo, v.77, n.1, p.91-98, 2010.

30. Teruel, B.J.M. Tecnologias de resfriamento de frutas e hortaliças. Revista Brasileira de Agrociência, Pelotas, v.14, n.2, p.199-220, 2008.

31. Werner, E.L.; Oliveira Junior, L.F.G.Bona, A.P.; Cavati, B.; Gomes, T.D.U.H. Efeito do cloreto de cálcio na pós-colheita de goiaba Cortibel. Bragantia, Campinas, v.68, n.2, 511-518, 2009.

32. Yusof, S. Physico-chemical characteristics of some guava varieties in Malaysia.Acta Horticulturae, Bélgica, n.269, p.301-305, 1990. 